\title{
UMA ANÁLISE COMPARATIVA ENTRE OS INDICADORES DE DESEMPENHO DO BALANCED SCORECARD E PRÊMIO NACIONAL DA QUALIDADE NA VISÃO DA CONTROLADORIA*
}

\author{
Elza Hofer \\ Wagner Dias da Silva \\ Cláudio Parisi
}

\begin{abstract}
Resumo
O presente artigo tem por objetivo elaborar uma pesquisa bibliográfica, acerca dos indicadores de performance estabelecidos pelo Balanced Scorecard (BSC) e os critérios de excelência propostos pela Fundação do Prêmio Nacional de Qualidade (FPNQ), para o Prêmio Nacional de Qualidade (PNQ). Apresenta também, uma análise comparativa entre as duas ferramentas analisadas. Conclui-se que os critérios de excelência estabelecidos pela FPNQ corrobaram com os interesses da sociedade, pois, contemplam atitudes e padrões que valorizam o ser humano e o meio ambiente, tornando as empresas mais preparadas para assegurar a sua sustentabilidade a longo prazo, por estarem sincronizadas com as novas dinâmicas que afetam a sociedade e o mundo empresarial. Portanto, à luz da Controladoria, tanto o BSC quanto o PNQ podem ser considerados como ferramentas que permitem o controle através de indicadores de performance dos eventos que compõem as diversas perspectivas, estabelecidas no processo de planejamento da empresa e colocadas em prática no processo de gestão.
\end{abstract}

Palavras-chave: Indicadores de Desempenho, Prêmio Nacional da Qualidade, Controladoria

\section{A COMPARATIVE ANALYSIS BETWEEN PERFORMANCE INDICATIVE OF BALANCED SCORECARD AND PRÊMIO NACIONAL DA QUALIDADE UNDER MANAGEMENT ACCOUNTING VIEW}

\begin{abstract}
The present article aims to elaborate a bibliographical research, regarding performance indicatives established by Balanced Scorecard (BSC) and the excellence criteria proposed by Fundação Prêmio Nacional da Qualidade (FPNQ), for the Prêmio Nacional de Qualidade $(P N Q)$. It also shows a comparative analysis between both analyzed tools. It is concluded that the excellence criteria established by FPNQ corroborated to the society interests, because they share attitudes and patterns that valorize the human being and the environment letting the companies better prepared to assure its long term sustainability, for being synchronized to new dynamics that affect the society and the entrepreneurial world. So, to the light of the Management Accouting, even the BSC as the $P N Q$, can be considered tools that allow the control through event's performance indicatives that compound such several perspectives, established in the company's planning process and put into practice in the manager process.
\end{abstract}

Keywords: Performance indicatives; Prêmio Qualidade Nacional; Controllership.

\footnotetext{
* O artigo foi apresentado e publicado nos ANAIS da XXXIX Asamblea Anual CLADEA, 2004, Puerto Plata - República Dominicana.
} 


\section{Introdução}

Os recentes avanços tecnológicos e a globalização dos mercados observados no século passado provocaram mudanças profundas na competitividade e no ambiente das empresas em geral. Necessita-se, cada vez mais, utilizar sistemas que permitam aos gestores a adequada avaliação de desempenho da organização. Essas necessidades vão além dos controles financeiros dos resultados já incorridos. Na sua elaboração, faz-se necessário, incluir atributos como: qualidade dos produtos, satisfação dos clientes, capital intelectual, os intangíveis em geral, entre outros que normalmente não são considerados.

Nesta perspectiva, surge o Balanced Scorecard (BSC), desenvolvido por Kaplan e Norton, apresentado inicialmente em 1992 como ferramenta de gestão estratégica. No Brasil, outra ferramenta a ser considerada é o Prêmio Nacional de Qualidade, instituído em 1991 pela Fundação Nacional do Prêmio de Qualidade, que estabelece critérios de excelência para avaliação de desempenho das empresas, com base em padrões internacionais.

Assim, a presente pesquisa tem por objetivo desenvolver um estudo bibliográfico, analisando os conceitos do BSC, busca-se, também, apresentar uma análise comparativa com os critérios de excelência estabelecidos pela FPNQ e destacar a importância do BSC e FPNQ para a evolução do modelo de avaliação de desempenho proposto pela controladoria. Esta finalidade nos remete a seguinte questão básica da pesquisa: qual é a relação entre os critérios de excelência FPNQ e os indicadores de desempenho do BSC como instrumento de gestão da controladoria? Como hipótese principal, esta pesquisa parte do pressuposto de que os critérios de excelência do PNQ são mais abrangentes que os indicadores de desempenho contemplados pelo BSC.

A presente pesquisa, além desta introdução, apresenta mais três tópicos e a conclusão. No segundo tópico faz-se uma revisão conceitual da controladoria e apresenta-se uma visão da controladoria moderna. Posteriormente, no terceiro tópico discute-se os conceitos do BSC e FPNQ. No quarto tópico faz-se uma análise comparativa entre as quatro perspectivas do BSC e os critérios de excelência estabelecidos pela FPNQ. Por fim, a última parte destina-se à conclusão da pesquisa.

\section{A Controladoria}

A controladoria surgiu no início do século XX nas grandes corporações norte-americanas. Estas foram influenciadas por três fatores que marcaram o desenvolvimento industrial daquela época: verticalização, diversificação de atividades e a expansão geográfica das organizações que, aliadas, ao aumento da complexidade e a uma tendência de descentralização da gestão fizeram com que surgisse a figura do controller. Atualmente, a competitividade e as constantes mudanças necessárias para garantir a sobrevivência e continuidade da empresa, exige dos gestores, conforme Peleias (2002, p. 13), a possibilidade de "identificar alternativas de ação, quantificá-las e escolher aquela que permita o alcance dos objetivos da organização".

Neste contexto, a Controladoria, enquanto órgão administrativo, tem a incumbência de fornecer informações rápidas e precisas, além de ferramentas que facilitem o processo de 
tomada de decisão para suportar os gestores na escolha da melhor alternativa de ação. Para Peleias (2002, p. 13), a controladoria é "uma área da organização à qual é delegada autoridade para tomar decisões sobre eventos, transações e atividades que possibilitam o adequado suporte ao processo de gestão".

Nesta perspectiva, percebe-se que a controladoria existirá em uma empresa, quer sua estrutura organizacional a tenha ou não como uma unidade administrativa. Mosimann; Fisch (1999, p. 97), ratificam este posicionamento, ao afirmarem que quando não existe na empresa a controladoria como órgão administrativo, a coordenação dos esforços para a busca da maximização dos resultados globais da empresa será exercida por outro gestor, entretanto deverá ser sempre aquele que tiver a maior visão generalista.

Portanto, trata-se de um órgão dotado de missão, objetivos e metas para a sua própria atuação. Almeida, Parisi; Pereira in Catelli (1999, p. 372), mencionam que a missão da contoladoria é "assegurar a otimização do resultado econômico da organização". Para que a missão seja cumprida, objetivos claros e viáveis deverão ser estabelecidos.

Nesta perspectiva, a missão e os objetivos da controladoria devem estar em consonância com a missão e a continuidade da empresa. Entretanto, cabe à controladoria funcionar como indutora da evolução da cultura organizacional como um todo, a fim de promover a melhoria da qualidade das decisões, pois sua atuação, para ser eficaz, envolve a implementação de um conjunto de ações, cujos resultados materializam-se em informações de orientação e controle disponibilizados aos gestores.

\subsection{A Controladoria no Apoio ao Processo de Gestão}

As funções da controladoria estão ligadas a um conjunto de objetivos e ao serem desempenhadas viabilizam o processo de gestão. Para Peleias (2002, p. 14), ”o processo de gestão está inserido no subsistema de gestão. É o principal processo decisório da empresa e é composto pelas etapas de planejamento, execução e controle. Esse processo precisa ser adaptado à realidade da organização e deve ser estruturado dentro de uma seqüência ordenada de etapas". Neste sentido, as contribuições da controladoria para o processo de gestão, conforme Peleias (2002, p. 14), são:

a)

b)

c) subsídio à etapa de planejamento, com informações e instrumentos que permitam aos gestores avaliar o impacto das diversas alternativas de ação sobre o patrimônio e os resultados da organização, e atuar como agente aglutinador de esforços pela coordenação do planejamento; operacional;

subsídio à etapa de execução por meio de informações que permitam comparar os desempenhos reais nas condições padrão e realizado pelo registro dos eventos e transações efetivamente concluídos;

subsídio à etapa de controle, permitindo a comparação das informações relativas à atuação dos gestores e áreas de responsabilidade com o que se obteve com os produtos e serviços, relativamente a planos e padrões previamente estabelecidos. Nessa etapa ocorrem as avaliações de desempenho e de resultado; e a contribuição da controladoria nesse processo é:

- $\quad$ elaboração e análise do desempenho dos gestores, das diferentes áreas da empresa e de sua própria atuação, pois também é uma das áreas de responsabilidade que deve contribuir para o cumprimento da missão da organização; 
- definição das regras de realização da análise dos resultados gerados pelos produtos e serviços, participação, monitoramento e orientação do processo de estabelecimento de padrões para eventos, transações e atividades, bem como a avaliação do resultado dos serviços que presta à organização.

\subsection{A Controladoria como Apoio ao Sistema de Informações}

A controladoria deverá disponibilizar um sistema de informações gerenciais para suportar o processo de gestão com informações adequadas, nas decisões requeridas em suas diversas etapas. Nesta perspectiva Peleias (2002, p.15), afirma que "a informação é a base e o resultado da ação executiva. A partir dessa constatação, é preciso empreender esforços para suprir os gestores com ferramentas de informática que permitam o planejamento, o registro e o controle das decisões tomadas em cada fase do processo de gestão".

Portanto, o exercício eficiente dessa função pressupõe de conhecimento e correta interpretação das determinações do modelo de gestão, adotada pela organização e dos modelos de decisão, mensuração e de informação, permitindo, assim, ajustes das alterações causados pelas variações entre os desempenhos planejados e realizados e evidenciando, desta forma, o impacto das variáveis externas e internas sobre o desempenho da empresa, através das variações orçamentárias.

\subsection{As Características da Controladoria Moderna}

Para Martin (2002, p. 13), "a controladoria começa com o entendimento de que todos os recursos que são mobilizados e utilizados pelas organizações têm um objetivo maior: produzir valor". Nesta perspectiva, a transformação produtiva, convertendo recursos em bens e ou serviços, pressupõe a existência de mercado e demanda econômica. Essa transformação de recursos gera custos e deve, conseqüentemente com os seus produtos, produzir valor para os clientes e usuários, bem como para os acionistas e ou investidores. Martin (2002, p 15), afirma que:

\footnotetext{
adotando a representação dos objetivos e metas de uma empresa a partir da dupla produção competitiva de valor, a Controladoria dá um passo essencial para entender o mundo empresarial atual. Seus levantamentos, análises e demonstrativos não mais irão padecer da dimensão unidimensional e unicamente financeira dos resultados das organizações. Um desempenho empresarial não mais poderá ser julgado apenas pela métrica financeira do retorno aos seus investidores, já que se sabe que a sustentação desse retorno no tempo (o grande objetivo dos investidores) somente se dará se houver continuidade na satisfação dos clientes/usuários em relação a seus produtos.
}

Fica evidente, diante das ponderações do autor, que os intangíveis passam a fazer parte do processo de gestão das empresas, subsidiando os gestores, com informações para o desempenho empresarial, pois, a continuidade da empresa depende de fatores intrínsecos e extrínsecos que ultrapassam as métricas financeiras.

Nesta perspectiva, a controladoria precisa ser intrinsecamente estratégica para atender às necessidade da gestão moderna, o que deve ser feito com o apoio operacional. Deste modo, a controladoria precisa ter a compreensão da própria natureza da empresa e de seus objetivos, bem como do ambiente em que ela está inserida e com o qual interage, tais como: mercado, 
concorrência, tecnologia, entre outros, que podem afetar diretamente os resultados das empresas em determinado segmento ou ramo de atividade.

Neste contexto, Martin (2002, p.25), apresenta as características da controladoria moderna, conforme ilustrado na Figura 1. Ressalta também, que as transformações recentes, no panorama mundial da contabilidade gerencial, têm imensas implicações para o ensino e na formação de controllers, ou seja, busca preparar controllers mais generalistas com capacidade de entender a empresa como um todo.

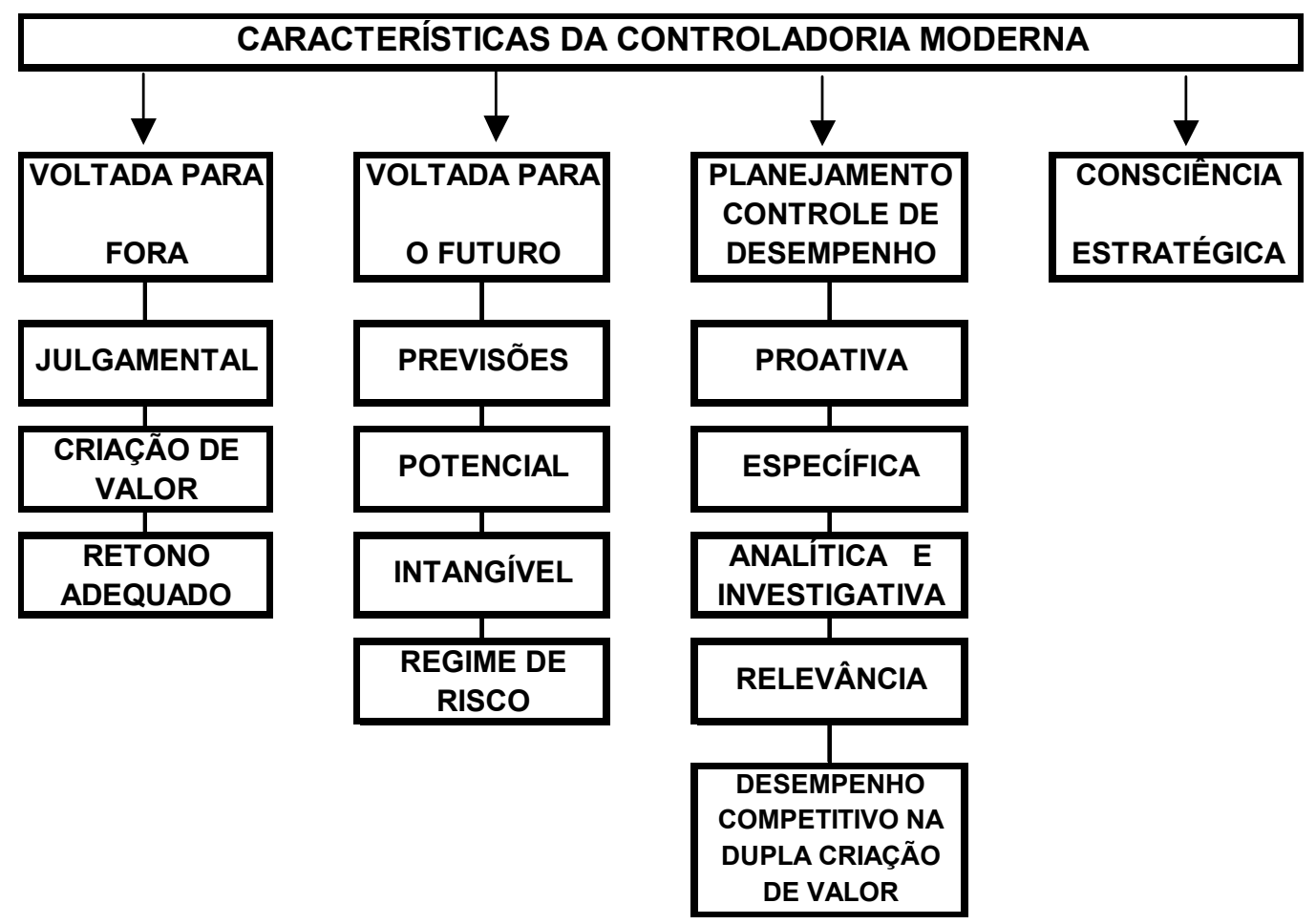

Figura 1 -As características da controladoria moderna

Fonte: Martin (2002, p. 25), adaptada.

À luz destes conceitos, faz-se uma abordagem do Balanced Scorcared, e do PNQ com o intuito de propiciar informações aos gestores para que possam melhorar a avaliação do desempenho proposto pela controladoria.

\section{Balanced Scorecard e o Prêmio Nacional da Qualidade}

Conforme Costa (2001), o ambiente competitivo, de rápidas mudanças, impõe aos gestores necessidades não só de avaliar o desempenho passado, mas também, de saber se eles estão criando valor futuro. A criação de valores exige a exploração de valores intangíveis. Na era da informação, saber explorar ativos intangíveis é mais importante que saber investir e administrar ativos físicos.

Para Lunkes (2002), diante das atuais mudanças no mercado e os inadequados métodos de mensuração, as empresas vêm buscando novas formas de melhorar seus sistemas de 
informações, o que ocorre, por meio de sistemas de mensuração financeiros e não financeiros. Um exemplo dessas ferramentas é o balanced scorecard.

O conceito apresentado para Balanced Scorecard, por Kaplan; Norton (1997), considera uma companhia a partir de quatro perspectivas vitais: perspectivas financeiras, perspectivas processo interno, perspectivas do cliente e perspectivas de aprendizagem e crescimento, conforme pode ser observado na figura 2. $O B S C$ procura vincular o controle operacional de curto prazo à visão de longo prazo e estratégia do negócio, forçando a companhia a controlar e monitorar as funções do dia-a-dia. Portanto, o conceito do BSC baseia-se em três dimensões no tempo: ontem, hoje e amanhã.

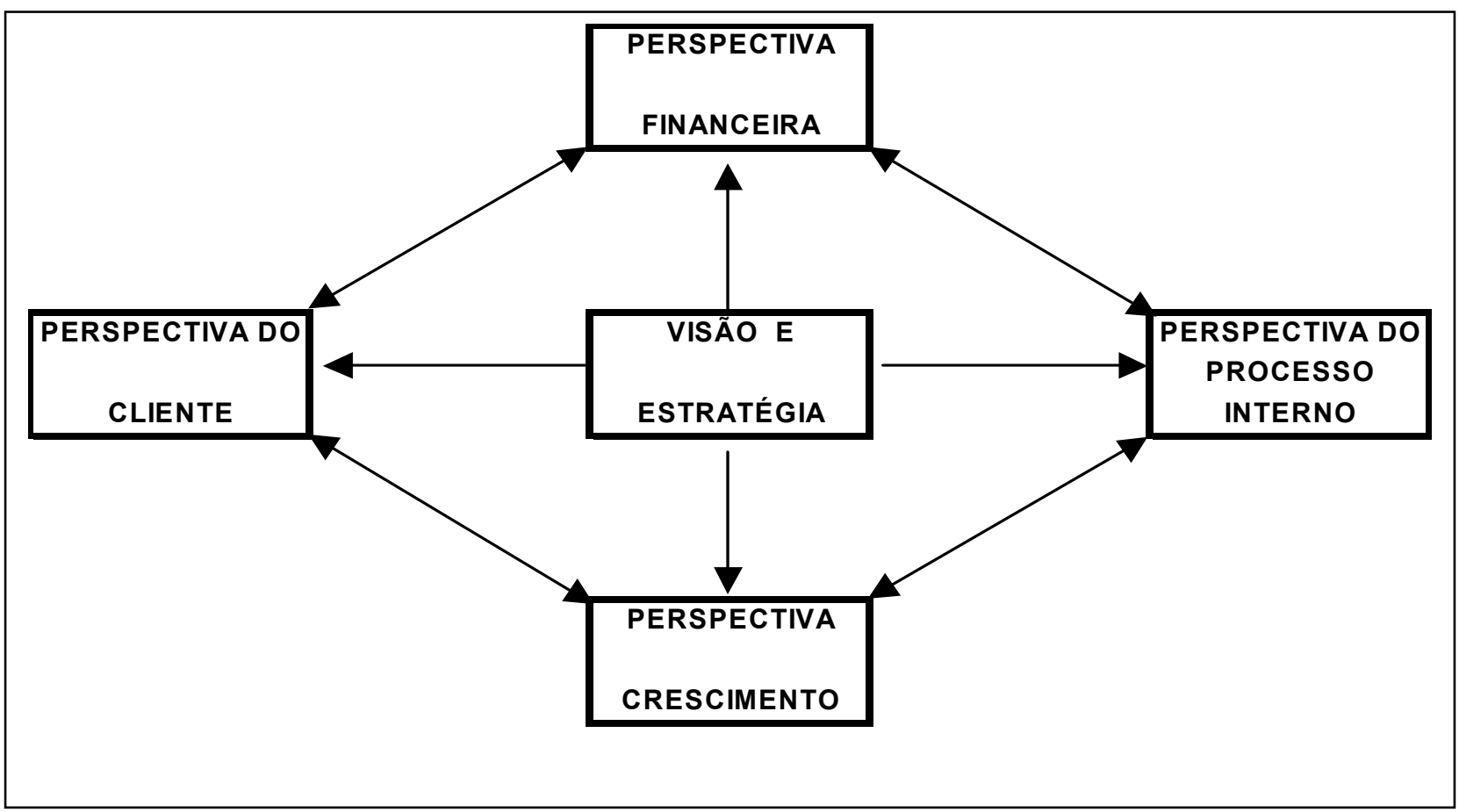

Figura 2 - Descrição de Kaplan; Norton do processo do Balanced Scorecard.

Fonte: Elaborada pelos autores com base na descrição de Kaplan e Norton 1997.

A seguir, descrevem-se as quatro perspectivas do BSC, na visão dos autores, Kaplan; Norton (1997), a financeira, a do cliente, a de processos internos e a de aprendizagem e crescimento.

\subsection{A Perspectiva Financeira}

Para Kaplan; Norton (1997, p. 49), os indicadores do BSC devem relatar a história durante a implementação da estratégia, começando pelas metas financeiras de longo prazo e relacionando-os, posteriormente, à seqüência de atividades relativas aos processos financeiros, dos clientes, dos processos internos e, dos funcionários e sistemas. O objetivo é que, a longo prazo, seja produzido o desempenho econômico desejado.

As metas financeiras da organização devem estar vinculadas à sua estratégia e os indicadores de desempenho, sob esta perspectiva, devem servir de foco principal para os objetivos e 
medidas das outras perspectivas do BSC. Para Kaplan; Norton (1997, p. 65), as medidas selecionadas devem fazer parte de uma cadeia de relações causa e efeito que resultam na melhoria do desempenho financeiro.

As fases do ciclo de vida das empresas podem classificar-se em: crescimento, sustentação e colheita. De acordo com os autores Kaplan; Norton (1997, p. 59), para cada uma dessas fases, existem três temas financeiros, que norteiam a estratégia empresarial: crescimento e mix de receita, redução de custos, melhoria de produtividade, utilização dos ativos e estratégia de investimento.

Por outro lado, há que se considerar que, além disso, dois objetivos normalmente são perseguidos pelas organizações: a maximização do retorno sobre o investimento e a maximização da riqueza dos proprietários. No que se refere ao retorno sobre o investimento, normalmente se toma uma taxa de referência chamada de custo de oportunidade de capital da empresa.

Os objetivos de crescimento e mix de receita correspondem ao crescimento da oferta de produtos e serviços, conquista de novos clientes e mercados, mudança no mix de produtos e serviços para itens de maior valor agregado entre outros. Os objetivos de redução de custos e melhoria de produtividade referem-se a iniciativas de reduzir os custos diretos e indiretos, bem como, compartilhar com outras unidades da organização. Nos objetivos de utilização dos ativos, os gestores podem reduzir os níveis de capital de giro necessários para sustentar um determinado volume e mix de operações.

Verifica-se que o $B S C$ permite tornar os objetivos financeiros explícitos ajustando-os de acordo com cada uma das fases dos ciclos de vida do crescimento de uma empresa. Kaplan; Norton (1997), afirmam que os Scorecards conhecidos utilizam objetivos financeiros tradicionais relacionados à lucratividade, ao retorno sobre os ativos e ao aumento da receita. As empresas acreditam que estas medidas oferecem os elos de ligação entre as quatro perspectivas do $B S C$.

\subsection{A Perspectiva do Cliente}

As empresas identificam os segmentos de clientes e mercado nos quais desejam competir. A perspectiva dos clientes permite que as empresas alinhem suas medidas essenciais de resultado relacionados aos clientes como: satisfação, fidelidade, retenção, captação e lucratividade com segmentos específicos de clientes e mercado, que correspondem às fontes que irão produzir o componente de receita e objetivos financeiros da empresa. Permitem, também, uma clara identificação e avaliação dos indicadores de tendências, dirigida a esse segmento.

Neste contexto, Kaplan; Norton (1997, p. 72), afirmam que o grupo de medidas essenciais de resultado dos clientes, comum a todos os tipos de empresa, inclui os seguintes indicadores:

- Participação de Mercado: Reflete a proporção de negócios num determinado mercado (em termos de clientes, valores gastos ou volume unitário vendido).

- Captação de Clientes: Mede, em termos absolutos ou relativos, a intensidade com que uma unidade de negócios atrai ou conquista novos clientes ou negócios. 
- Retenção de Clientes: Controla, em termos absolutos ou relativos, a intensidade com uma unidade de negócios retém ou mantém relacionamentos contínuos com seus clientes.

- Lucratividade dos Clientes: Mede o lucro líquido de cliente ou segmentos, depois de deduzidas as despesas específicas necessárias para sustentar esses clientes.

Conforme Kaplan ; Norton (1997, p. 77), as propostas de valor variam de acordo com o setor de atividades e os diferentes segmentos de mercado. Observa-se a existência de atributos que permitem a ordenação em todos os setores para os quais são elaborados Scorecards. Esses atributos são divididos em três categorias: atributos de tributos e serviços; relacionamento com os clientes; imagem e reputação.

Os atributos de produtos e serviços correspondem à funcionalidade, preço, e qualidade dos produtos e ou serviços. O relacionamento dos clientes diz respeito à entrega do produto e ou serviço ao cliente no tempo de resposta considerada e no requisito de conforto do cliente em relação à compra. Por fim, a dimensão de imagem e reputação corresponde aos reflexos dos fatores intangíveis que atraem um cliente para empresa.

Diante do exposto, verifica-se que os clientes são a razão da existência do negócio, como geradores de recursos. Por isso, medidas devem ser desenvolvidas para acompanhar as possíveis mudanças nos valores e preferências dos clientes em relação aos produtos e serviços da organização.

\subsection{A Perspectiva dos Processos Internos}

Kaplan; Norton (1997, p. 97), afirmam que os executivos devem identificar os processos mais críticos para realizar os objetivos dos clientes e acionistas. As empresas costumam desenvolver objetivos e medidas para essa perspectiva após desenvolver as medidas para as perspectivas financeiras e do cliente. Essa seqüência permite que as empresas focalizem as métricas dos processos internos nos processos que conduzirão aos objetivos dos clientes e acionistas.

Os indicadores de desempenho derivam de objetivos e medidas estratégicas e devem ser definidos através da cadeia de valor completo dos processos internos para a criação de valor para os clientes e produção de resultados financeiros.

Kaplan; Norton (1997, p. 101), afirmam que um modelo genérico de cadeia de valor inclui três processos principais: inovação, operações e serviço pós-venda. No processo de inovação, as empresas identificam as necessidades emergentes ou latentes dos clientes atuais e desenvolvem novos produtos ou serviços, que atenderão essas necessidades, permitindo-lhes atingir novos mercados e clientes.

No estágio de processo de operações, os produtos ou serviços são produzidos e oferecidos aos clientes. É neste processo que as empresas mais se focalizam para indicadores de desempenho. Medidas de tempo, qualidade e custo são normalmente utilizados em processos operacionais. Por fim, o serviço pós-venda que corresponde a serviço de apoio e suporte 
realizado para o cliente após a venda e ou entrega dos produtos e ou serviços. Por exemplo, atividades de garantia e conserto, correção de defeitos e devoluções.

Nesta perspectiva, observa-se que os indicadores dos processos internos são de significativa importância, pois é a partir desta perspectiva que as empresas podem identificar característica de custo, qualidade, tempo e desempenho. Isto permite que elas ofereçam produtos e ou serviços de qualidade superior, que os seus concorrentes, refletindo os objetivos de desempenho financeiro aos acionistas.

\subsection{A Perspectiva de Aprendizagem e Crescimento}

Kaplan; Norton (1997, p.131), definem na quarta e última perspectiva do $B S C$, os indicadores de desempenho para orientar o aprendizado e o crescimento organizacional. Os objetivos dessa perspectiva devem facilitar e possibilitar a colocação em prática de todos os outros objetivos presentes nas três perspectivas. Para o setor industrial, três categorias podem ser definidas para a perspectiva de aprendizado e crescimento: capacidade dos funcionários, capacidade dos sistemas de informação, motivação, empowerment e alinhamento.

A transformação do papel dos funcionários, nas organizações, surgiu porque cada vez mais as idéias dos funcionários permitem melhorar os processos e o desempenho para com os clientes. Existe um grupo de três medidas essenciais para os funcionários: satisfação, retenção, e produtividade.

A dimensão da capacidade dos sistemas de informação envolve o fornecimento de todas as informações sobre clientes, os processos internos e as conseqüências financeiras de suas decisões para os funcionários de linha de frente, gerentes e executivos. Algumas empresas utilizam indicadores de cobertura de informações estratégicas para avaliação da disponibilidade atual das informações com relação às informações, necessárias previstas.

No que se refere à terceira dimensão, aprendizagem e crescimento, ou seja, a dimensão da motivação, empowerment e alinhamento focalizam o clima organizacional para motivação e a iniciativa dos funcionários. Estas medidas de motivação e empowerment podem ser medidas de várias formas. Por exemplo, número de sugestões apresentadas por funcionário.

Conforme Kaplan; Norton (1997, p. 152), as capacidades organizacionais, para o aprendizado e o crescimento, definem a capacidade da organização de alcançar as metas estratégicas para os objetivos financeiros dos clientes e dos processos internos. Portanto, fica evidente que os objetivos e medidas para esses vetores de desempenho devem fazer parte do $B S C$ de qualquer empresa. Porém, caso seja necessário, existe a possibilidade de agregar um ou mais vetores de desempenho sob outras perspectivas complementares.

Nesta perspectiva, percebe-se que o $B S C$ pode viabilizar quatro processos gerenciais críticos, conforme Kaplan; Norton (1997), quais sejam: esclarecer e traduzir a visão e a estratégia; comunicar e associar objetivos e medidas estratégicas; planejar, estabelecer metas e alinhar iniciativas estratégicas; e melhorar o feedback e o aprendizado estratégico. Portanto, o BSC deve fazer parte do sistema de informações para os funcionários de todos os níveis da 
organização, bem com deve ser utilizado como sistema de informação, comunicação e aprendizado das estratégias durante a sua implementação.

Após dez anos de publicação do primeiro artigo, cogita-se a possibilidade de se agregar novas perspectivas ao modelo inicial, como os próprios autores sugeriram. As quatro perspectivas não são condições suficientes, pois o atual ambiente competitivo exige o compromisso e a responsabilidade social da empresa com a comunidade, o meio ambiente, assim como a promoção de ações socialmente justas.

\section{O Prêmio Nacional da Qualidade - PNQ}

Segundo a FPNQ (2002 p. 05), o domínio do conhecimento na área de avaliação, utilizando um modelo adequado, aliado a um Código de Ética seguido rigorosamente pelas Bancas Examinadoras e as sucessivas atualizações implementadas nos Critérios de Excelência, a partir da troca de informações com as instituições congêneres no exterior, geraram a credibilidade que hoje sustenta o Prêmio Nacional da Qualidade (PNQ).

O PNQ estimula a melhoria da qualidade da gestão das organizações brasileiras, reconhecendo anualmente aquelas que atingiram o nível de desempenho de "Classe Mundial", ou seja, organizações destacadas pela excelência da gestão de suas práticas e respectivos resultados, promovendo interna e externamente, a reputação de excelência dos produtos e serviços brasileiros e divulgando as práticas exemplares da gestão.

Atualmente, os fundamentos da excelência que servem de referencial para os Critérios de Excelência do PNQ são conforme a FNPQ (2002 p.13): Liderança e constância de propósitos, Visão de Futuro, Foco no cliente e no mercado, Responsabilidade social e ética, Decisões baseadas em fatos, Valorização das pessoas, Abordagem por processos, Foco nos resultados, Inovação, Agilidade, Aprendizado organizacional e Visão Sistêmica.

Observa-se pela análise do relatório anual divulgado pela FNPQ que o Modelo de Excelência busca refletir a experiência, o conhecimento e o trabalho de pesquisa de muitas organizações e especialistas do Brasil e do exterior, nestes doze anos de existência.

Em função da sua flexibilidade, da simplicidade da linguagem utilizada e, principalmente, por não prescrever ferramentas e práticas de gestão específicas, o Modelo é útil para avaliação, diagnóstico e orientação de qualquer tipo de organização, no setor público ou privado, com ou sem finalidade de lucro e de pequeno, médio ou grande porte. A incorporação dos fundamentos da excelência às operações da organização, de maneira continuada e em consonância com seu perfil e suas estratégias, é enfatizada pelo Modelo proposto. A seguir são elencados os oito Critérios de Excelência utilizados pela FNPQ. 


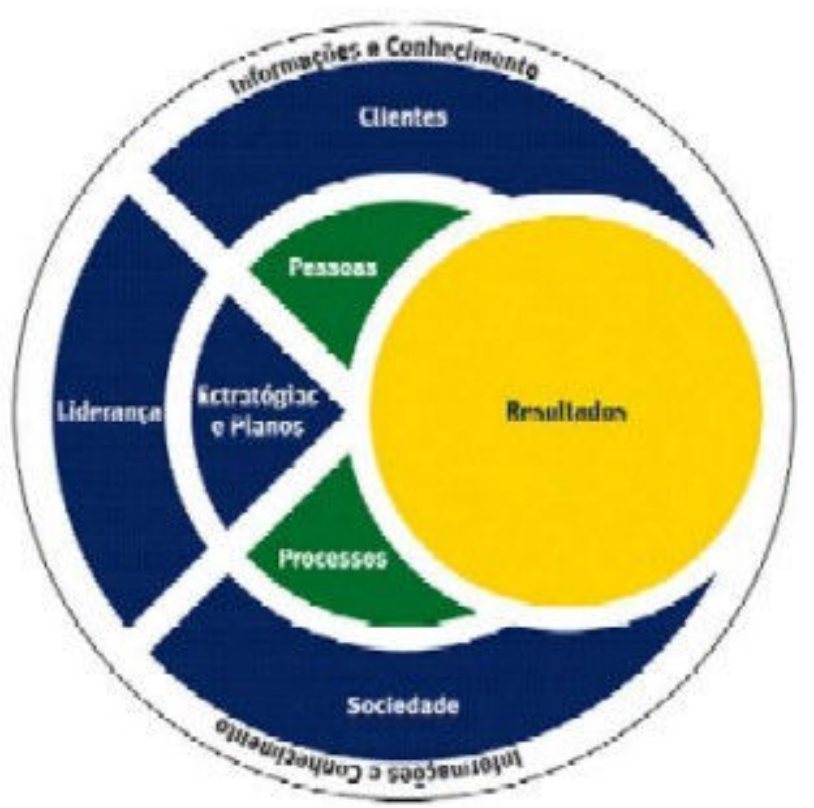

Figura - Os oito critérios de excelência da FNPQ Fonte FNPQ (2002 p. 01)

A análise da figura representativa do Modelo de Excelência do PNQ mostra um modelo de relacionamento entre a organização, considerada como um sistema adaptável gerador de produtos e informações e seu ambiente organizacional e tecnológico, além do próprio ambiente externo ao qual a entidade esteja inserida.

De acordo com a FNPQ, os resultados são o grande orientador para o acompanhamento do desempenho da organização e suas tendências, em relação aos clientes e ao mercado, à situação econômico-financeira, às pessoas, aos fornecedores, aos processos relativos ao produto, à sociedade, aos processos de apoio e aos processos organizacionais. Desta forma, e a partir da constante obtenção da adequada combinação destes fatores é que a organização consegue manter a sua continuidade frente ao concorrido cenário em que ela atua.

Verifica-se, que segundo a FNPQ a sobrevivência e o sucesso de uma organização estão diretamente relacionados à sua capacidade de atender às necessidades de seus clientes. Assim, essas necessidades devem ser identificadas, entendidas e utilizadas para que os produtos possam ser desenvolvidos, criando o valor necessário para conquistar e reter esses clientes.

A continuidade da entidade depende também do atendimento das necessidades da sociedade com a qual a organização convive. Desta forma, de acordo com o FNPQ as entidades também devem identificar, entender e satisfazer as necessidades da sociedade e das comunidades com as quais interage, cumprindo as leis, preservando os ecossistemas e contribuindo com o desenvolvimento das mesmas, dentro da mais transparente ética.

Verifica-se, que segundo o FNPQ, as pessoas que compõem a força de trabalho devem estar capacitadas e satisfeitas, atuando em um ambiente propício à consolidação da cultura da excelência para executarem e gerenciarem adequadamente os processos, identificarem as melhores alternativas de captações, aplicações de recursos e utilizarem os bens e serviços 
provenientes de fornecedores para transformá-los em produtos, criando, assim, valor para os clientes, de acordo com o que estabelecem as estratégias e os planos da organização.

Verifica-se que os processos se caracterizam pela identificação das melhores alternativas de captações e aplicações de recursos e a utilização dos bens e serviços provenientes de fornecedores para transformá-los em produtos, criando, assim, valor para os clientes, de acordo com o que estabelecem as estratégias e os planos da organização.

Observa-se que, os líderes, principais responsáveis pela obtenção de resultados que assegurem a satisfação de todas as partes interessadas e a perpetuidade da organização, analisam criticamente o desempenho global da mesma e tomam, sempre que necessário, as ações requeridas, consolidando, assim, o controle e o aprendizado organizacional.

As estratégias são formuladas pelos líderes para direcionar a organização e o seu desempenho, bem como para determinar a sua posição competitiva. As Estratégias são desdobradas em planos de ação, para curto e longo prazos, e servem como referência para a tomada de decisões e para a aplicação de recursos na organização. Para permitir a comunicação clara das diretrizes organizacionais e das estratégias para as partes interessadas, direcionar a sua implementação e possibilitar a análise crítica do desempenho global pela liderança, é planejado e operacionalizado o sistema de medição do desempenho da organização.

Os efeitos gerados pelas práticas de gestão e pela dinâmica externa à organização podem ser comparados às metas estabelecidas durante a definição das estratégias e planos para eventuais correções de rumo ou para reforços das ações implementadas. Esses resultados, em forma de informações e conhecimento retornam para toda a organização para que esta possa tomar as ações e buscar o aprendizado organizacional.

Essas informações representam a inteligência da organização, viabilizando a análise crítica e a tomada das ações necessárias, em todos os níveis. A figura enfatiza as informações e o conhecimento como elementos que permitem a ligação e o correlacionamento entre todos os critérios e, portanto, todos os elementos que constituem a organização. As gestões da informação e do capital intelectual são elementos essenciais para a jornada, em busca da excelência.

\section{Comparação entre as Perspectivas do BSC e os Critérios de Excelência do PNQ}

Uma análise comparativa entre os preceitos concebidos por Kaplan e Norton e os critérios de excelência estabelecidos pelo PNQ e as principais diferenças entre ambos podem ser observadas no Quadro 1: 


\begin{tabular}{|c|c|c|}
\hline \multicolumn{3}{|c|}{$\begin{array}{c}\text { COMPARAÇAO ENTRE AS PERS PECTIVAS DO BS C } \\
\text { E OS CRITERIOS DE EXCELENCIA DO PNQ }\end{array}$} \\
\hline \begin{tabular}{|l|} 
PERS PECTIVA/ \\
CRITÉRIO D E EXCELENCIA
\end{tabular} & BS C & PNQ \\
\hline FIN ANC EIRA & $\begin{array}{l}\text { Interesses de longo prazo da } \\
\text { organização, }\end{array}$ & $\begin{array}{l}\text { Os resultados são o grande orientador } \\
\text { para o acompanhamento do } \\
\text { desempenho da organização e suas } \\
\text { tendências em relação aos clientes e ao } \\
\text { mercado, }\end{array}$ \\
\hline CLIEN TE & $\begin{array}{l}\text { M edidas essenciais de resultado } \\
\text { relacionados aos clientes como } \\
\text { satisfação, fidelidade, retenção, } \\
\text { captação e lucratividade com } \\
\text { segmentos específicos de clientes e } \\
\text { mercado, }\end{array}$ & $\begin{array}{l}\text { Necessidades identificadas, entendidas } \\
\text { e utilizadas para que os produtos } \\
\text { possam ser desenvolvidos, criando } \\
\text { valor necessário para conquistar e reter } \\
\text { clientes. }\end{array}$ \\
\hline $\begin{array}{l}\text { PROCES S OS } \\
\text { INTERNOS }\end{array}$ & $\begin{array}{l}\text { Necessidades } \\
\text { emergentes ou } \\
\text { latentes dos clientes atuais e } \\
\text { desenvolvem novos produtos/ } \\
\text { serviços, que atenderão essas } \\
\text { necessidades, permitindo-lhes } \\
\text { atingir novos mercados e clientes. }\end{array}$ & $\begin{array}{l}\text { M elhores de alternativas } \\
\text { captações/ap licação } \\
\text { recursos e serviços provenientes de } \\
\text { fornecedores e transformá-los em } \\
\text { produtos de valor aos clientes. }\end{array}$ \\
\hline $\begin{array}{l}\text { APREN DIZAGEM E } \\
\text { CRES CIMENTO }\end{array}$ & $\begin{array}{l}\text { Cap acidade dos funcionários; } \\
\text { cap acidade dos sistemas de } \\
\text { informação; motivação, } \\
\text { empow erment e alinhamento. }\end{array}$ & $\begin{array}{l}\text { Pessoas capacitadas e satisfeitas, } \\
\text { atuando em um ambiente propício } \\
\text { à consolidação da cultura da excelência } \\
\text { erecutarem/gerenciarem } \\
\text { adequadamente os processos. }\end{array}$ \\
\hline S O C IED AD E & Não contemp lada & $\begin{array}{l}\text { Identificar, entender e satisfazer as } \\
\text { necessidades da Sociedade cumprindo } \\
\text { leis, preservando os } \\
\text { ecossistemas e contribuindo com o } \\
\text { desenvolvimento }\end{array}$ \\
\hline $\begin{array}{l}\text { ES TRATÉGIAS E } \\
\text { PLANOS }\end{array}$ & Não contemp lada & $\begin{array}{l}\text { Formuladas por líderes para direcionar } \\
\text { a } \\
\text { organização e o desemp enho, bem } \\
\text { como para determinar } \\
\text { a sua posição comp etitiva. }\end{array}$ \\
\hline LID ERAN ÇA & Não contemp lada & $\begin{array}{l}\text { Estabelece valores e as diretrizes da } \\
\text { organização, pratica e vivencia os } \\
\text { fundamentos da } \\
\text { excelência, impulsionando, a } \\
\text { disseminação da cultura da excelência }\end{array}$ \\
\hline $\begin{array}{l}\text { INFO RMAÇÕ ES E } \\
\text { CONHECIMENTO }\end{array}$ & Não contemp lada & $\begin{array}{l}\text { Correlacionamento entre critérios com } \\
\text { os elementos que constituem a } \\
\text { organização. A gestão do capital } \\
\text { intelectual é essencial p ara a } \\
\text { excelência. }\end{array}$ \\
\hline
\end{tabular}

Quadro 1 - Comparação entre as perspectivas do BSC e os critérios de excelência do PNQ Fonte: Elaborado pelos autores

Comparativamente ao $B S C$, verifica-se que o PNQ se mostra mais flexível e abrangente nos critérios e perspectivas adotados, na medida em que contempla critérios de excelência, 
capazes de se adequar aos parâmetros estabelecidos pelas entidades para a avaliação de seu desempenho, bem como por refletir também as necessidades da sociedade que a empresa pode atender, alinhando-se, assim, com os conceitos de responsabilidade social atualmente difundidos.

\section{O BSC e PNQ Como Ferramentas de Avaliação de Desempenho Proposta Pela Controladoria}

Dentre as diversas ações que compõem o processo de gestão da empresa, verifica-se uma série de procedimentos que se notabilizam pela averiguação da confirmação da ocorrência ou não daquilo que foi planejado. Esse procedimento caracteriza-se pelo controle, o que no entendimento de Peleias (2002, p. 26), consiste "na etapa do processo de gestão, contínua e recorrente, que avalia o grau de aderência entre os planos e sua execução, analisa os desvios ocorridos, procurando identificar suas causas, sejam elas internas ou externas".

A avaliação, dentro do contexto empresarial, pode ensejar duas vertentes igualmente importantes, mas diferentes em seu escopo: a avaliação de resultados e a avaliação de desempenho. A primeira denota um caráter de eficiência, na medida em que se refere à forma de execução das atividades em um determinado período. Para Peleias (2002, p. 26); "avaliação de resultados é a aferição das decisões tomadas pelos gestores sobre eventos e transações, que ocorrem na empresa, evidenciando no que os esforços foram aplicados e o que se obteve".

Já a avaliação de desempenho diz respeito à eficácia ao atingir as metas planejadas, através da adequada utilização dos recursos disponíveis. Para sua adequada mensuração se faz necessário a definição de um plano ou objetivo a atingir. Segundo Peleias (2002, p. 28), a avaliação de desempenho "é a mensuração da gestão das funções específicas, considerando receitas, custos variáveis e fixos e suas implicações nos desempenhos e resultados das áreas de responsabilidade e da empresa, através das decisões dos gestores em seus níveis planejado e realizado".

Diante deste conceito, pode-se entender que mensuração difere de avaliação, pois esta se refere a questões como julgamento, atribuição de valor e aquela expressa o significado quantitativo da avaliação. Para Pereira in Catelli (1999, p. 190), mensurar "refere-se à quantificação dos atributos de um objeto, com o intuito de expressá-lo numericamente".

Desta forma, a avaliação de desempenho consiste na mensuração dos diversos eventos pertinentes ao processo de gestão, a partir de parâmetros pré-estabelecidos e que orientem a atuação de todos os setores, em benefício de toda a organização, ou seja, todas as ações devem estar em perfeita harmonia e consonância com o objetivo maior da empresa.

O estabelecimento dos parâmetros que compõem a base de mensuração para a avaliação de desempenho através do $B S C$ e do PNQ é obtido, como visto, a partir do sistema de informações contábeis-financeiras da empresa. Neste aspecto, ambos se mostram em consonância com a controladoria, na medida em que esta também recorre às informações desta natureza para a realização de suas atividades. 
Os conceitos abordados, nesta pesquisa, acerca da aplicação do $B S C$ e do PNQ como ferramentas gerenciais que permitem o conhecimento e acompanhamento por meio de diversos indicadores, através dos eventos que compõem as perspectivas da empresa, podem, à luz da controladoria, ser considerados como uma das maneiras de se avaliar o desempenho da empresa, na medida em que aderem a uma série de características mencionadas por Peleias (1992, p.149), ao contemplar alguns aspectos pertinentes à avaliação de desempenho, dentre as quais, destaca-se:

- A avaliação de desempenho deve permitir às empresas verificarem se a atividade se desenvolve no sentido do atendimento à estratégia previamente definida. Quando tal atingimento não ocorrer, deve permitir a identificação da origem do problema, de modo a possibilitar a sua pronta eliminação.

- A avaliação de desempenho dos gestores e das áreas de responsabilidade deve contemplar os aspectos operacionais, financeiros e econômicos das atividades a serem executadas.

- Os critérios e conceitos a serem utilizados na avaliação de desempenho deverão ser definidos no modelo de gestão da empresa, e deverão ser do conhecimento e do consenso das áreas de responsabilidade.

- Os gestores deverão, idealmente, participar da elaboração dos planos da empresa, para que seu desempenho seja avaliado com base nos planos por eles elaborados.

- Poderão ser utilizados parâmetros não-financeiros para avaliação de desempenho dos gestores e das áreas de responsabilidade, os quais deverão ser determinados em função do tipo de atividade.

- A avaliação de desempenho dos gestores e das áreas de responsabilidade deverá ser suportada por informações oportunas e tempestivas, as quais deverão refletir o resultado das decisões tomadas na fase do planejamento (...).

Verifica-se, que o $B S C$ e o PNQ se alinham à Controladoria na medida em que:

- Traduzem a visão e as estratégias da empresa em uma linguagem comum a todos os seus componentes;

- Assim como a Controladoria propõe o confronto do Orçamento Previsto com o Realizado, os indicadores de desempenho do BSC e do PNQ servem como parâmetro a ser confrontado com os resultados efetivamente ocorridos.

- Os indicadores de desempenho são convertidos em metas que deverão ser alcançadas e ações que deverão ser implementadas para alcançar essas metas.

\section{Conclusões}

Concluiu-se, através da elaboração dessa pesquisa bibliográfica de abordagem crítica sobre os conceitos acerca do tema, que o $B S C$ não se notabiliza pelo seu pretenso caráter de inovação, na medida em que se verifica a existência de modelos anteriores à sua divulgação, os quais contemplam, em seu bojo, características idênticas às apregoadas por Kaplan e Norton. Através da análise comparativa entre as duas ferramentas, constatou-se que o PNQ se mostra como uma ferramenta mais abrangente que o $B S C$, por contemplar um número maior de critérios que servem de parâmetro para a avaliação de desempenho das organizações.

Por outro lado, verifica-se que os critérios de excelência estabelecidos pela FPNQ corrobaram com os interesses da sociedade, pois, contemplam atitudes e padrões que valorizam o ser 
humano e o meio ambiente, tornando as empresas mais preparadas para assegurar a sua sustentabilidade a longo prazo, por estarem sincronizadas com as novas dinâmicas que afetam a sociedade e o mundo empresarial.

À luz da Controladoria, tanto o BSC quanto o PNQ podem ser considerados como ferramentas que permitem o controle através de indicadores de performance dos eventos que compõem as diversas perspectivas estabelecidas no processo de planejamento da empresa e colocados em prática no processo de gestão.

Verifica-se, também, a necessidade do monitoramento dos indicadores de desempenho, assim como seus aspectos críticos favoráveis e desfavoráveis, realizando-se esforços de feedback e aprendizado estratégico, traduzindo-os na revisão e análise dos planos e ações implementados, realimentando continuamente, o processo de gestão.

\section{Referências}

ALMEIDA, Lauro Brito de, PARISI, Cláudio; PEREIRA, Carlos Alberto. Controladoria In: CATELLI, Armando (coordenador) Controladoria: uma abordagem da gestão econômica GECON. 2. ed. São Paulo: Atlas, 2001.

COSTA, A. P. P. Contabilidade Gerencial: um estudo sobre a contribuição do Balanced Scorecard. São Paulo: 2001. Dissertação (Mestrado)- FEA USP.

FPNQ - Fundação para o Prêmio Nacional da Qualidade. Manual do Prêmio Nacional da Qualidade. Critérios de Excelência para 2003. São Paulo, 2003.

LUNKES, R. J. Estudo sobre a integração entre Balanced Scorecard e o orçamento. Revista Brasileira de Contabilidade. Brasília. no 136 p. 49-59 julho/agosto 2002.

KAPLAN, R. S. ; NORTON, D. P. A Estratégia em Ação: Balanced Scorecard. Rio de Janeiro: Campus, 1997.

MARTIN, N. C. Da contabilidade à controladoria: a evolução necessária. Revista Contabilidade \& Finanças. São Paulo: ano XIII n n 28 p. 7-28 janeiro/abril 2001.

MOSIMANN, C. P. ; FISCH, S. Controladoria; seu papel na administração de empresas. 2. ed. São Paulo: Atlas, 1999.

PELEIAS, I. R. Controladoria: gestão eficaz utilizando padrões. São Paulo: Saraiva, 2002.

Avaliação de desempenho: um enfoque da gestão econômica São Paulo. Faculdade de Economia e Administração da Universidade de São Paulo. 1992. Dissertação (Mestrado) -FEA-USP 